\title{
Mortality of asbestos workers in England and Wales 1971-81
}

\section{J T HODGSON AND R D JONES}

From the Epidemiology and Medical Statistics Unit, Health and Safety Executive, Bootle, Merseyside, UK

ABSTRACT A national study of British asbestos workers is briefly described and the mortality experience of 31150 male asbestos workers in England and Wales who had been medically examined at least once as part of that survey is presented. The survey population is divided into workers with occupational exposure to asbestos before the inception of the 1969 Asbestos Regulations and those who worked with asbestos only after 1969. Of the 1128 who had died, 897 had worked before 1969; 34 of the death certificates received for these men mentioned mesothelioma and for another nine asbestosis was reported in the absence of mesothelioma or lung cancer. A statistically significant excess of lung cancer (SMR 136) was found. For the post-1969 workers, one case of asbestosis and one case of mesothelioma were reported, but further investigation of these cases showed probable occupational exposure to asbestos many years before 1969. The time from first exposure for this section of the population is too short to exclude an excess of asbestos related disease. The most noticeable excess of asbestos related disease was seen among the insulation workers who had more than twice (SMR 256) the expected number of deaths from lung cancer, and for whom almost $10 \%$ of all death certificates mentioned mesothelioma. No excess of any alimentary tract cancer was found and the population showed a significant deficit of large bowel cancer mortality (SMR 54).

In parallel with the introduction of the 1969 Asbestos Regulations ${ }^{1}$ a national survey of asbestos workers was set up as the preferred alternative to statutory medical surveillance. In this paper we describe the survey as it relates to the collection of data for mortality analysis and the results of that analysis for male workers in England and Wales up to and including 31 December 1981.

\section{Methods}

\section{POPULATION}

The population was defined as everyone employed in a factory or workplace which attracted the 1969 Asbestos Regulations. The nominal roll was compiled from those individuals employed in each workplace at the start of recruitment to the survey plus those workers who subsequently started work in that workplace. Recruitment was supervised by medical officers who were also responsible for the collection of medical information on the study population. For larger workplaces supervision was generally carried out by the works medical officer (WMO) who re-

Accepted 23 July 1985 cruited workers into the survey once they started to work with asbestos. Where a WMO was not in post, individuals were recruited into the survey by employment medical advisers who visited companies at roughly two yearly intervals.

\section{INFORMATION RECORDED}

Workers in the survey were seen at two yearly intervals for medical examination and completion of a questionnaire giving details of identification, smoking habit, occupational history, and duration of exposure to asbestos. This procedure continued for as long as the worker remained in that particular employment. $\rightarrow$ Identification details on each individual were sent to the NHS Central Register (NHSCR) where the sub- N ject's register entry was traced and "flagged." When any survey subject dies the Office of Population Censuses and Surveys (OPCS) sends survey control a copy $C$ of the death certificate with the underlying cause coded to the International Classification of Diseases 6 (ICD) revision in use at the time of death registration.

The occupational hygiene section of Her Majesty's ? Factory Inspectorate carried out a programme of measurement of exposure levels in many of the workplaces covered by the survey. Since the asbestos 
related mortality examined by the present report will be related to exposure levels in the 1950s and 1960s, however, and the earliest measurements in the occupational hygiene programme were taken in 1972, there is little point in attempting to relate the mortality observed here with the available exposure data. Similar considerations apply to the information available on the types of fibre to which individuals in the survey were exposed, as this relates only to their exposures since the start of the survey. The present report does not therefore present any analyses in terms of exposure levels or fibre type.

The data on individuals' smoking habits collected as part of the survey have been used in the present analysis only to quantify the probable effect of smoking on the study population's SMR for lung cancer. We intend at a later date to examine and report on the interaction between the effects of smoking and exposure to asbestos on lung cancer mortality.

\section{CODING OF DEATH CERTIFICATES}

Each death certificate sent to survey control was coded by OPCS for the underlying cause of death in accordance with the ICD revision in use by OPCS at the time.

To present a more coherent picture of asbestos related disease (ARD) some ICD codes were modified. All death certificates with a mention of mesothelioma have been given a special code and treated as deaths with an underlying cause "mesothelioma." The interpretation of the mention of asbestosis on death certificates is difficult because of the loose way in which the term seems sometimes to be used (particularly by coroners). Thus where it is considered that a person has died from carcinoma of the bronchus or from mesothelioma caused by asbestos, the word "asbestosis" may be put on the death certificate to indicate the link between exposure to asbestos and death, rather than the existence of fibrosing alveolitis. For this reason the only deaths counted to asbestosis as underlying cause were those where the death certificate mentioned asbestosis in the absence of mesothelioma or lung cancer.

CALCULATION OF EXPECTED MORTALITY RATES Person-years at risk were calculated by taking the time from the date of the first examination up to whichever was the earliest of the following dates: date of death, date of emigration, or 31 December 1981. The personyears at risk were subdivided into 12 five year age bands from age 15 upwards, with a 13th residual age band for 75 years and over. Person-years were also subdivided into three calendar year periods, 1970-4, 1975-8, 1979-81. Expected deaths were calculated by applying the corresponding age-epoch-cause specific England and Wales male death rates. SMRs have been calculated in the usual way - that is SMR equals observed deaths divided by expected deaths times 100 . Because of the specificity of mesothelioma and asbestosis to exposure to asbestos SMRs are not calculated for these diseases; instead the numbers of deaths from these causes have been expressed as a percentage of the expected mortality from all causes in order to adjust roughly for differences in numbers and age structure between population subgroups.

The SMR calculations were performed using the OCMAP computer program produced by Pittsburgh University. ${ }^{2}$

\section{Results}

By the end of 1981, 33079 men working in England and Wales had been entered into the survey. Table 1 shows the status of these subjects in respect of tracing at NHSCR and of their acceptance of medical surveillance. The trace rate for examined men was $98.5 \%$, whereas for men who declined to be examined the rate was only $82 \%$. This difference arises because the identification details available for men declining to be examined were in general less complete than for examined men. Also, information on date of first exposure to asbestos was unknown for most unexamined workers. For both these reasons, unexamined workers were excluded from the present analysis, which is based on the records of the 31150 traced and examined men.

Table 2 shows the mortality analysis for the ICD groupings chosen as being of first order interest. The population has been split into those who work with asbestos only after the 1969 regulations and those who had worked both before and after the introduction of the 1969 legislation. Both subsets of the population show an overall deficit of mortality largely due to the decreased mortality from circulatory and respiratory disorders which is consistent with a "healthy worker effect." 3 There is a pronounced excess of lung cancer among the pre-regulations men that is statistically significant at the $1 \%$ level. There is a small nonsignificant increase in lung cancer in men working only after the 1969 regulations. The total population has a deficit of cancer of the large bowel. This is largely due to the shortfall in deaths from cancer of the colon among the pre-regulations population which reaches statistical significance at the $1 \%$ level.

Table 1 Status of tracing

\begin{tabular}{lrrr}
\hline & Examined & Not examined & Total. \\
\hline Traced & 31150 & 1423 & 32573 \\
Not traced & 415 & 91 & 506 \\
Total & 31565 & 1514 & 33079 \\
\hline
\end{tabular}


Table 2 Mortality of workers exposed to asbestos before and after 1969 regulations

\begin{tabular}{|c|c|c|c|c|c|c|c|c|}
\hline \multirow{3}{*}{$\begin{array}{l}\text { Cause of } \\
\text { death }\end{array}$} & \multicolumn{4}{|c|}{ Exposure before regulations } & \multicolumn{4}{|c|}{ Exposure only after regulations } \\
\hline & \multicolumn{2}{|c|}{ Total period of follow up } & \multicolumn{2}{|c|}{$\begin{array}{l}\text { Excluding follow up for } \\
\text { initial } 10 \text { years after 1st } \\
\text { exposure to asbestos }\end{array}$} & \multicolumn{2}{|c|}{ Total period of follow up } & \multicolumn{2}{|c|}{$\begin{array}{l}\text { Excluding follow up for } \\
\text { initial } 10 \text { years after lst } \\
\text { exposure to asbestos }\end{array}$} \\
\hline & $O / E$ & $S M R$ & $O / E$ & $S M R$ & $O / E$ & $S M R$ & $O / E$ & $S M R$ \\
\hline All causes & $897 / 1011 \cdot 8$ & $88 \cdot 7 * *$ & $834 / 931 \cdot 6$ & $89 \cdot 5^{* *}$ & $231 / 273 \cdot 7$ & $84 \cdot 4^{* *}$ & $9 / 9 \cdot 5$ & $94 \cdot 8$ \\
\hline $\begin{array}{l}\text { Oesophagus } \\
\text { Stomach } \\
\text { Colon } \\
\text { Rectum } \\
\text { Lung } \\
\text { Circulatory } \\
\text { disease }\end{array}$ & $\begin{array}{c}6 / 9 \cdot 4 \\
27 / 27 \\
6 / 16 \cdot 7 \\
10 / 12 \cdot 9 \\
157 / 121 \cdot 0 \\
426 / 509 \cdot 7\end{array}$ & $\begin{array}{c}63 \cdot 7 \\
100 \cdot 2 \\
36 \cdot 0^{* *} \\
77 \cdot 3 \\
129 \cdot 7^{* *} \\
83 \cdot 6^{* *}\end{array}$ & $\begin{array}{c}6 / 8 \cdot 8 \\
24 / 24 \cdot 9 \\
5 / 15 \cdot 4 \\
9 / 12 \\
152 / 112 \cdot 1 \\
395 / 471 \cdot 5\end{array}$ & $\begin{array}{c}68 \cdot 5 \\
96 \cdot 3 \\
32 \cdot 5^{*} \\
75 \cdot 0 \\
135 \cdot 6^{* *} \\
83 \cdot 8^{* *}\end{array}$ & $\begin{array}{c}1 / 2 \cdot 3 \\
5 / 6 \cdot 1 \\
4 / 4 \cdot 1 \\
0 / 3 \cdot 1 \\
29 / 26 \cdot 9 \\
101 / 122 \cdot 3\end{array}$ & $\begin{array}{c}44 \\
82 \cdot 7 \\
97 \cdot 2 \\
108 \cdot 0 \\
82 \cdot 6\end{array}$ & $\begin{array}{l}0 / 0 \cdot 9 \\
0 / \cdot 2 \\
0 / \cdot 2 \\
0 / \cdot 1 \\
1 / 1 \cdot 0 \\
6 / 4 \cdot 6\end{array}$ & $\begin{array}{l}\bar{Z} \\
\overline{-} \\
96.2 \\
129.6\end{array}$ \\
\hline $\begin{array}{l}\text { Respiratory } \\
\text { disease }\end{array}$ & $64 / 92 \cdot 4$ & $69 \cdot 3^{* *}$ & $61 / 85 \cdot 4$ & $71 \cdot 4^{* *}$ & $14 / 20.7$ & $67 \cdot 6$ & $1 / \cdot 8$ & $123 \cdot 5$ \\
\hline $\begin{array}{l}\text { Asbestosis } \\
\text { Mesothelioma }\end{array}$ & $\begin{array}{l}11(1.1 \%) \\
34(3.4 \%)\end{array}$ & & $\begin{array}{l}11(1.2 \%) \\
34(3.6 \%)\end{array}$ & & $\begin{array}{l}1(0.4 \%) \\
1(0.4 \%)\end{array}$ & & $\begin{array}{l}0 \\
0\end{array}$ & \\
\hline
\end{tabular}

Table 3 shows mortality from cancers of the alimentary tract in the pre-regulations population by cumulative exposure. The deficit of cancer of the colon is equally pronounced in each exposure category. The SMRs for oesophageal and rectal cancer show slight upward trends with increasing exposure, but these are far from statistically significant, and the overall SMRs are well below 100 . Mortality from stomach cancer decreases with increasing exposure to asbestos, though again the trend is not statistically significant.

Eleven of the 12 death certificates mentioning asbestosis in the absence of mesothelioma or lung cancer were in the preregulations population, where they comprised just over $1 \%$ of all death certificates. Thirty four of the 35 certificates mentioning mesothelioma came from the pre-regulations population where they accounted for almost $4 \%$ of all certificates. The duration of follow up of any individual in the postregulations population from the date of first exposure cannot by definition be in excess of 12 years. Because of latency considerations the finding of one case of asbestosis and one case of mesothelioma in the post- 3 regulations group was surprising. These two cases were therefore looked at in greater detail.

The man who had had asbestosis recorded on his $\vec{\theta}$ death certificate died in 1980 at the age of 58 . He had $\stackrel{\circ}{\circ}$ been entered into the survey in 1975 and his date of first exposure to asbestos recorded as March 1972. Inspection of the previous occupational history showed that the man had worked as a carpenter in dockyard towns since 1932, had been a carpenter with $\Phi$ the Royal Navy for six years, and had worked for a shipbuilding company since 1956 . Probably, therefore, the man had been exposed to asbestos at times over his long career as a shipyard carpenter, perhaps without being aware of this fact.

The man dying from mesothelioma reported a first $\stackrel{\varnothing}{\Phi}$ date of exposure to asbestos in 1971 but his detailed $?$ occupational history showed that he had worked in ship repairing and fitting out from 1942 until 1959. It was considered therefore that he probably received

Table 3 Mortality at selected alimentary tract cancer sites by cumulative exposure

\begin{tabular}{|c|c|c|c|c|}
\hline \multirow{2}{*}{$\begin{array}{l}\text { OBS/EXP } \\
\text { (SMR) }\end{array}$} & \multicolumn{3}{|c|}{ Cumulative exposure (years) } & \multirow[t]{2}{*}{ All exposures } \\
\hline & $<10$ & $10-20$ & $\geqslant 20$ & \\
\hline $\begin{array}{l}\text { Cancer of: } \\
\text { Oesophagus } \\
\text { Stomach } \\
\text { Colon } \\
\text { Rectum }\end{array}$ & $\begin{array}{l}0 / 1 \cdot 4 \\
6 / 4 \cdot 0 \\
(150) \\
1 / 2 \cdot 5 \\
(40) \\
1 / 1 \cdot 9 \\
(52)\end{array}$ & $\begin{array}{c}2 / 3 \cdot 1 \\
(65) \\
10 / 8 \cdot 6 \\
(116) \\
2 / 5 \cdot 5 \\
(36) \\
2 / 4 \cdot 2 \\
(47)\end{array}$ & $\begin{array}{c}4 / 5 \cdot 0 \\
(80) \\
11 / 14 \cdot 3 \\
(77) \\
3 / 5 \cdot 6 \\
(35) \\
7 / 6.8 \\
(103)\end{array}$ & $\begin{array}{l}6 / 9 \cdot 4 \\
(64) \\
27 / 26 \cdot 9 \\
(100) \\
6 / 16 \cdot 7 \\
(36) \\
10 / 12.9 \\
(77)\end{array}$ \\
\hline Total & $\begin{array}{l}8 / 9 \cdot 8 \\
(82)\end{array}$ & $\begin{array}{l}16 / 21 \cdot 4 \\
(75)\end{array}$ & $\begin{array}{l}25 / 34 \cdot 7 \\
(72)\end{array}$ & $\begin{array}{l}49 / 65 \cdot 9 \\
(74)\end{array}$ \\
\hline
\end{tabular}


Table 4 Observed/expected deaths and SMR for lung cancer by industry sector and cumulative expasure

\begin{tabular}{|c|c|c|c|c|c|c|c|c|c|}
\hline & & \multicolumn{8}{|c|}{ Industry sector } \\
\hline & & \multicolumn{4}{|l|}{ Asbestos } & \multirow[t]{2}{*}{ Insulation } & \multirow[t]{2}{*}{ Maintenance } & \multirow[t]{2}{*}{ Shipyards } & \multirow[t]{2}{*}{ Construction } \\
\hline & & Textiles & $\begin{array}{l}\text { Cement } \\
\text { board } \\
\text { \& pipe }\end{array}$ & $\begin{array}{l}\text { Mixtures } \\
\text { (resins, } \\
\text { rubber, } \\
\text { etc) }\end{array}$ & $\begin{array}{l}\text { Board } \\
\text { and } \\
\text { paper }\end{array}$ & & & & \\
\hline $\begin{array}{l}\text { Cumulative } \\
\text { exposure } \\
\text { (years) }\end{array}$ & $\begin{array}{l}<10 \\
>10\end{array}$ & $\begin{array}{l}3 / 5 \cdot 6 \\
53 \\
15 / 11 \cdot 2 \\
134\end{array}$ & $\begin{array}{l}6 / 7 \cdot 6 \\
79 \\
27 / 27 \cdot 0 \\
100\end{array}$ & $\begin{array}{l}13 / 12 \cdot 6 \\
103 \\
28 / 21 \cdot 5 \\
130\end{array}$ & $\begin{array}{l}2 / 2 \cdot 9 \\
68 \\
3 / 3.9 \\
77\end{array}$ & $\begin{array}{l}1 / 3 \cdot 9 \\
26 \\
42 / 12 \cdot 9 \\
347\end{array}$ & $\begin{array}{l}9 / 6 \cdot 5 \\
139 \\
16 / 14 \cdot 2 \\
113\end{array}$ & $\begin{array}{l}2 / 2 \cdot 9 \\
69 \\
12 / 10 \cdot 8 \\
111\end{array}$ & $\begin{array}{l}4 / 1 \cdot 3 \\
300 \\
2 / 1 \cdot 3 \\
154\end{array}$ \\
\hline
\end{tabular}

Table 5 Explicit asbestos related disease (ARD) mentioned on death certificates

\begin{tabular}{|c|c|c|c|c|c|c|c|c|}
\hline & \multicolumn{8}{|c|}{ Industry sector } \\
\hline & \multicolumn{4}{|l|}{ Asbestos } & \multirow[t]{2}{*}{ Insulation } & \multirow[t]{2}{*}{ Maintenance } & \multirow[t]{2}{*}{ Shipyards } & \multirow[t]{2}{*}{ Construction } \\
\hline & Textiles & $\begin{array}{l}\text { Cement } \\
\text { board } \\
\text { \& pipe }\end{array}$ & $\begin{array}{l}\text { Mixtures } \\
\text { (resins, } \\
\text { rubber, } \\
\text { etc) }\end{array}$ & $\begin{array}{l}\text { Board } \\
\text { and } \\
\text { paper }\end{array}$ & & & & \\
\hline $\begin{array}{l}\text { Deaths due to } \\
\text { mesothelioma }\end{array}$ & 0 & 6 & 7 & 1 & 17 & 1 & 3 & 0 \\
\hline $\begin{array}{l}\text { Deaths involving } \\
\text { asbestosis, other than } \\
\text { in conjunction with } \\
\text { mesothelioma }\end{array}$ & 3 & 7 & 3 & 2 & 23 & 0 & 1 & 2 \\
\hline Total explicit ARD & 3 & 13 & 10 & 3 & 40 & 1 & 4 & 2 \\
\hline
\end{tabular}

occupational exposure to asbestos for a substantial period before 1969. This view had also been taken by the Pneumoconiosis Medical Panel when awarding the man disablement benefit.

The indices of mortality for the three main asbestos related diseases, broken down by industry sector and, for lung cancer, by cumulative exposure are shown in tables 4 and 5 and figs 1 and 2 . Two of the 10 industry sectors defined within the survey cover very small numbers of people and are not included in these figures.

The breakdown by cumulative exposure is into two categories: under 10 years and over 10 years. Deaths are assigned to exposure categories in the obvious way, according to the category occupied by the decedent on the date of death. The associated expected numbers are calculated by splitting the person-years contributed by each survey subject at the point where the subject achieves 10 years exposure to asbestos and summing the under 10 years and over 10 years contributions separately. The fact that the longest possible exposure achievable by a survey subject first exposed after the 1969 Regulations is 11 years, means that the over 10 years figures relate almost exclusively (99\% of the expected deaths) to the preregulations exposed group. The relation of the under 10 years exposure figures with the postregulations group is less exclusive but still strong; two of the three expected deaths in this group arise from the postregulations group. For lung cancer the mortality index shown is the SMR. For mesothelioma and asbestosis, the numbers of deaths are expressed as a percentage of total expected deaths in each group. The bars on the figures represent the $95 \%$ confidence intervals.

The figures for deaths involving asbestosis other than in conjunction with mesothelioma are shown in table 5. They include 29 deaths with an underlying cause of lung cancer and the 12 deaths counted as due to asbestosis in the mortality analysis of the data in table 3. The outstanding feature of these figures is the high level of asbestos related disease in the insulation sector, which is the only sector in which, on the small number of observations so far to hand, all measures of ARD reach formal statistical significance (43 observed/16.8 expected for lung cancer). In all sectors except the maintenance "sector" and the construction sector, the lung cancer SMR is higher in the more than 10 years cumulative exposure category. Asbestosis or mesothelioma or both, is recorded in every sector.

Figure 3 shows the smoking prevalence recorded for people entering the asbestos survey compared with that found in the General Household Survey. The smoking habits of subjects in the asbestos survey tend to be heavier (by about 10 percentage points) than 

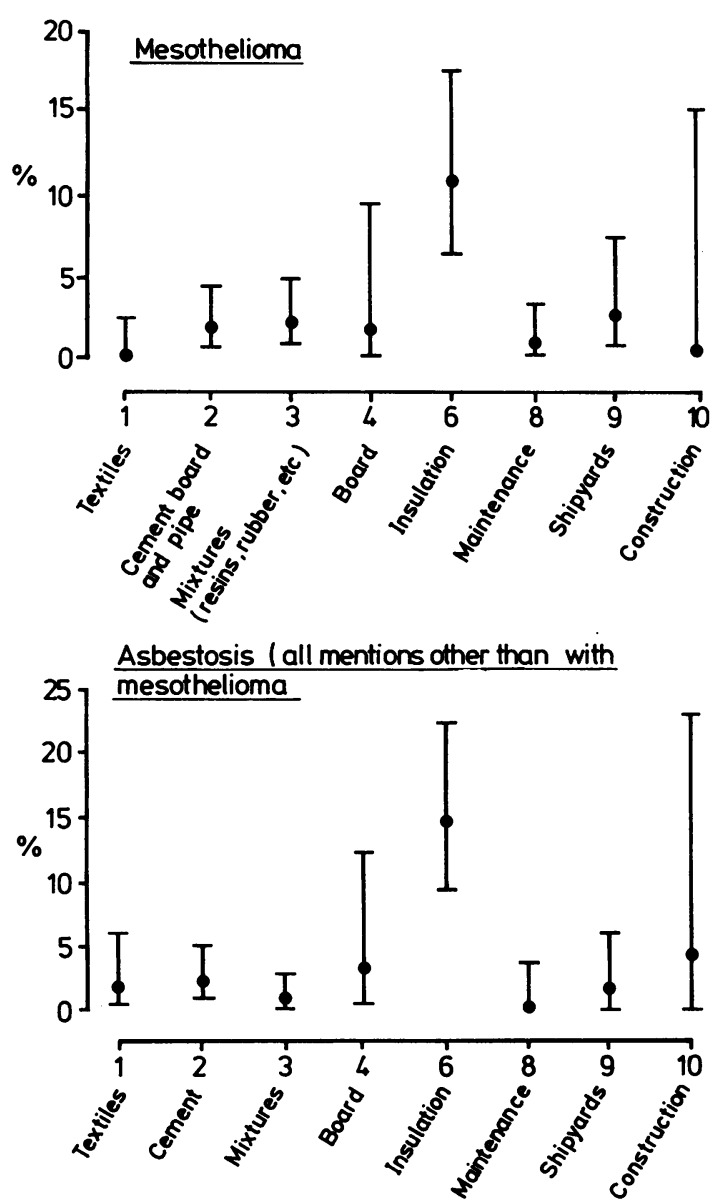

Fig 1 Explicit asbestos related disease on death certificates as percentage of total expected deaths, by industry sector with $95 \%$ confidence limits of observed percentages.

tend to be heavier (by about 10 percentage points) than those in the general population but the proportion of those who have ever smoked in the survey population is much closer to the national average.

\section{Discussion}

In a survey of this type where recruitment to the population has been carried out by a number of medical officers over several years, the way in which particular groups of workers have been included or excluded from the study are bound to have differed. Coverage of firms with no permanent workplace such as insulation contractors will be less complete than is the case for established factories. The population is made up of a cross sectional population (subjects in post at the start of recruitment) and a true cohort population $\frac{3}{8}$ (subjects joining on or after the first day of recruit- ? ment into the study at that workplace). The cross sectional population will be a survivor population and $\stackrel{F}{+}$ consist largely of individuals with pre-1969 exposure to asbestos.

Because of the substantial latent periods that are $\frac{\overline{\frac{\rho}{\sigma}}}{\bar{\phi}}$ generally associated with asbestosis, lung cancer, and $\stackrel{\mathbb{\Omega}}{\complement}$ particularly mesothelioma, it is too soon to expect to see any effect of exposure to asbestos on the mortality $\overrightarrow{0}$ of men exposed only after 1969 , even if such an effect exists. Thus the data here can show only the mortality $\vec{\omega}$ from asbestos related disease in the population of pre-1969 workers.

The fact that the only section of the study population in which it is sensible to look for asbestos re- $\frac{t}{\omega t}$ lated disease is cross sectional means that the picture $\omega$ of ARD that emerges may be subject to bias; and that $\vec{F}$ the contributions to risk of time related factors such ${ }^{\infty}$ as time from first exposure, duration of exposure, and 5 secular changes in exposure intensities, will to a large $\vec{z}$ extent be incapable of being distinguished from one another. This severely limits the range of conclusions $\stackrel{\widehat{\widehat{T}}}{\underline{\partial}}$ that may be drawn from the present analysis.

The limitations outlined above do not compromise $\ddot{\oplus}_{\infty}$ the two main qualitative conclusions for the present $\%$ analysis: that asbestos insulation workers bear a much 7 heavier burden of asbestos related disease than those in other sectors of the asbestos industry; and that, at least in this population of asbestos workers, exposure to asbestos is not associated with an increase in cancer $\stackrel{\unrhd}{\unrhd}$ of the alimentary tract.

The first of these conclusions is consistent with $\frac{\bar{O}}{3}$ other published epidemiological evidence, ${ }^{4-6}$ in which insulation workers have been seen to have consistently high levels of mortality from asbestos related disease with, typically, one in ten deaths due to meso- $\mathbb{D}$ thelioma, and about twice as many excess lung cancers as observed mesotheliomas. The picture of ARD re- 3 . ported elsewhere for other sectors of the asbestos industry is much more variable (as might be expected $\frac{1}{3}$ from the range of activities covered). The general pic- 0 ture is for the effects of ARD to be least in the asbestos cement $^{78}$ and asbestos mixtures ${ }^{9}$ sectors and greatest $\frac{7}{0}$ in the manufacture of insulation materials and of asbestos textiles. The pattern observed in the current $N$ study thus runs counter to expectation, with rather $N$ higher levels of mesothelioma and asbestosis in the cement and mixture sectors than in the board and $\omega$ paper and textiles sectors; though the confidence lim- $-\bar{r}$ its for these estimates are wide. When excess lung $O$ cancer is brought into the picture total ARD is similar $\mathbb{\Phi}$ in all four manufacturing sectors. When all sectors? other than the insulation sector are taken together, the $\frac{T}{0}$ numbers of excess lung cancers are about equal to the $\frac{\vec{O}}{\mathrm{D}}$ numbers of mesotheliomas observed, and whereas $\stackrel{\odot}{\mathbb{Q}}$ 


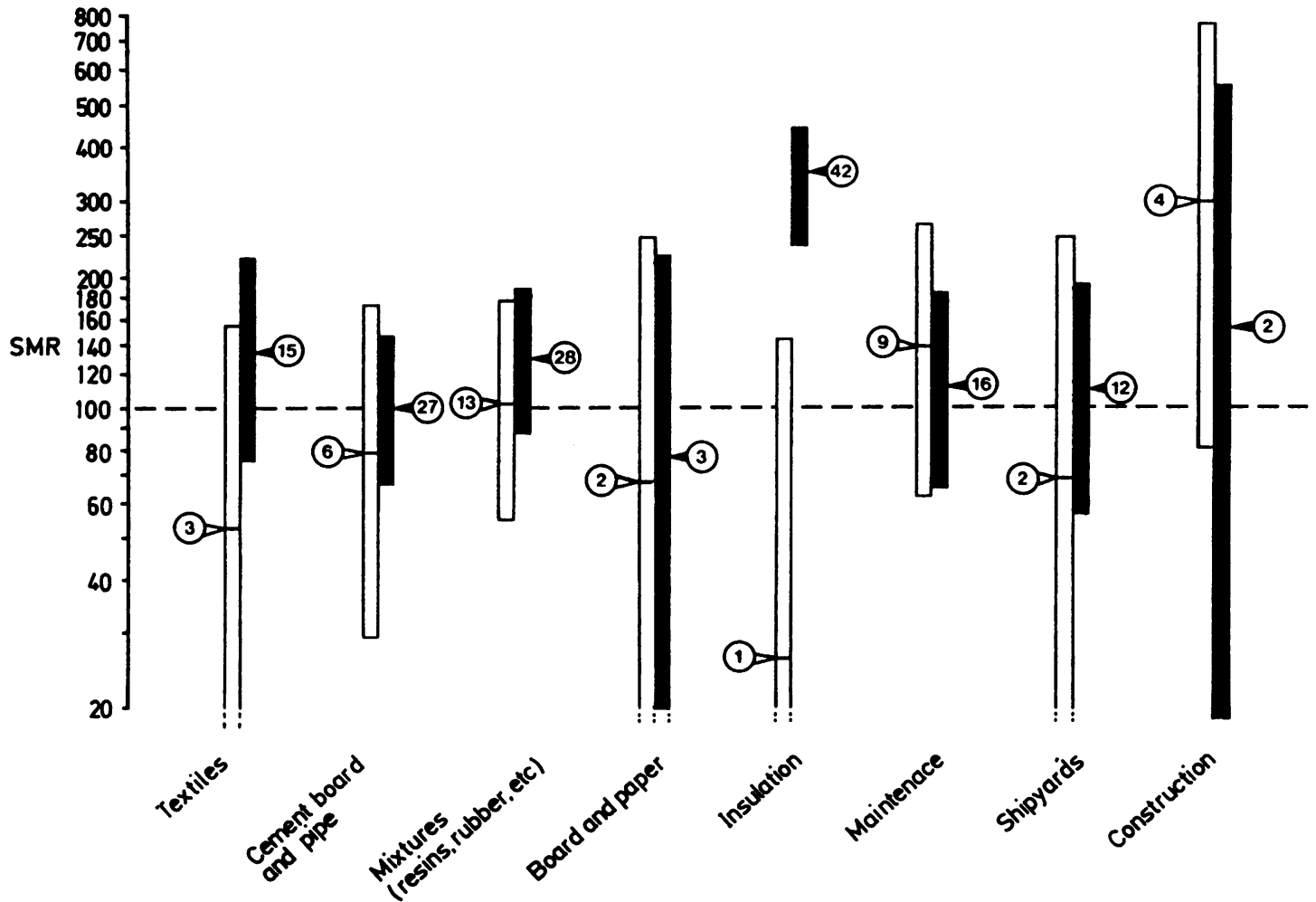

Fig 2 Lung cancer SMRs by industry sector and cumulative exposure ( $<10$ years $\triangleright,>10$ years 4$)$, showing numbers of observed deaths (in circles) and $95 \%$ confidence intervals.

similar relative levels have been observed in other studies, ${ }^{10}$ the general picture (except where crocidolite has been the fibre mainly responsible for the observed ARD), has been for excess lung cancers to be substantially more numerous than deaths from mesothelioma. The cross sectional nature of the population studied here, combined with the generally much longer induction period for mesothelioma than for lung cancer, will tend to increase the numbers of mesotheliomas recorded in relation to those for lung cancer, but the extent of this effect cannot be precisely quantified.

The considerable impact of ARD on insulation workers underlines the hazardous nature of asbestos exposure during stripping out of old insulation material. It is not yet possible to estimate the effect on this risk of ARD of the greater awareness of this problem and the introduction of safer working practices that have undoubtedly been a feature of the past 15 years since the introduction of the 1969 regulations. The Asbestos Licensing Regulations 1983 have ensured an even closer monitoring and supervision of work with asbestos insulation.

When considering mortality from bronchogenic lung cancer the role of cigarette smoking has to be taken into account. The prevalence of smoking in the general population has been decreasing since the beginning of the 1960s, and because of this changing pattern the number of people who have "ever smoked" may be a better index of relative risk of lung cancer in the period covered by this analysis than the number of people who are current smokers. On this measure the survey population is within two percentage points of the national average. An alternative approach is to look at smoking prevalence at a time

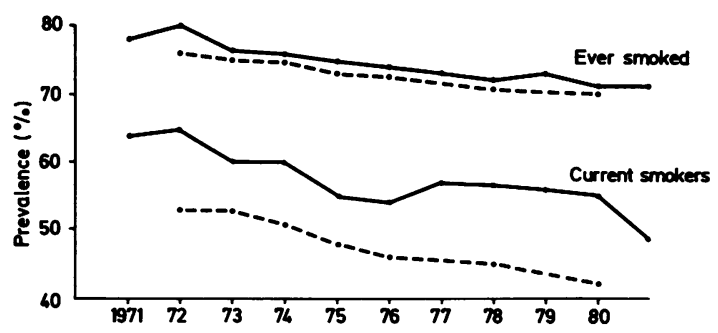

Fig 3 Smoking prevalence recorded at entry to asbestos survey (.—.) and in General Household Survey 


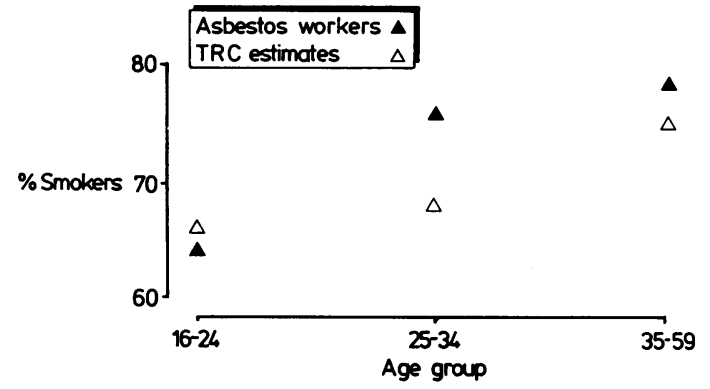

Fig 4 Smoking prevalence in 1961 of asbestos survey subjects over age 16 in 1961 compared with estimated national prevalence (Tobacco Research Council).

more likely to be relevant to deaths from lung cancer in the period covered. To do this we have calculated (from the age of first smoking reported) the smoking prevalence in 1961 of survey subjects who were over the age of 16 in that year. This calculation may be subject to recall bias since it is based on information gathered retrospectively. The results, however (fig 4) suggest that for the youngest age group (16-24) smoking was slightly less prevalent in the survey population than in the national population; for the two older age groups smoking was somewhat more prevalent - eight and four percentage points higher in the $25-34$ and 35-59 age groups respectively. Taking account of the relative contributions of these groups to the expected deaths in the period under observation, and allowing a 10 to 1 average relative risk for smokers compared with non-smokers, these differences would predict a lung cancer SMR for the survey population of about 105. Thus the slightly higher prevalence of smoking among the asbestos workers would produce only a small percentage increase in mortality from lung cancer and therefore the excess lung cancer found in the pre- 1969 population and among the insulators cannot be ascribed to difference in smoking habits.

The question as to whether exposure to asbestos leads to increased risk of cancers of the alimentary tract was initially posed by Selikoff's report on the mortality of US insulation workers, ${ }^{4}$ in which a threefold excess of gastrointestinal cancer was observed. The evidence from later studies is mixed, with some cohorts showing significant excesses ${ }^{1112}$ and others $^{7913}$ not. The small size of many of these studies no doubt explains a certain amount of this variability, but clearly there are genuine differences between the observed results. In a recent review Doll and Peto conclude that where excesses of alimentary tract cancer have been observed, these are most probably due to misdiagnosis of mesothelioma. ${ }^{14}$ This hypothesis is consistent with the fact that the strongest excesses of gastrointestinal cancers have been recorded in cohorts that also display a high risk of peritoneal mesothelioma.
The present study shows no excess from cancer at $\underset{\Phi}{\stackrel{Q}{0}}$ (oesophagus, stomach, colon, rectum), either overall or in association with increasing exposure to asbestos, $\stackrel{\mathcal{D}}{\rightarrow}$ nor among insulation workers, who showed heavy을 excesses of the established asbestos related diseases. 흠 The present results therefore weigh against the hy- $\frac{\bar{p}}{7}$ pothesis that exposure to asbestos is responsible for $\stackrel{\mathbb{}}{\varrho}$ an increase in the incidence of cancer of the alimentary tract.

Our report was made possible by virtue of much hard $\vec{\overrightarrow{ }}$ work put in by many of our colleagues and prede- $\omega$ cessors. In particular we wish to acknowledge Drs Trevor Lloyd-Davis and Morris Greenberg, Dr (now 3 Professor) John Fox, Patrick Collier, and Barry Werner. We are indebted to the many company $\omega$ medical officers and employment medical advisers $\vec{T}$ who have devoted a great deal of time to collecting $\infty$ basic data. We are grateful to the staff of OPCS for 은 flagging and tracing the population and providing coded death certificates. Lastly, we thank all the many $\overline{3}$ clerical staff who processed the data for the survey, and Mrs J Law who typed the numerous drafts of this $\supset$ report.

\section{References}

1 Asbestos Regulations 1969. (SI 1969/690.) London: HMSO, 1969.

${ }^{2}$ Marsh GM, Preininger M. OCMAP: a user-orientated occupational cohort mortality analysis program. American Statistician 1980;34:245.

${ }^{3}$ Fox AJ, Collier PF. Low mortality in industrial cohort studies due to selection for work and survival in the industry. Br J Prev Soc $\overline{\bar{O}}$ Med 1976;30:225-30.

${ }^{4}$ Selikoff IJ, Churg J, Hammond CE. Asbestos exposure and nepolasia. JAMA 1964;188:22-6.

${ }^{5}$ Selikoff IJ, Hammond EC, Seidman H. Mortality experience of insulation workers in the United States and Canada, 1943-76. Ann NY Acad Sci 1979;330:61-90.

${ }^{6}$ Elmes PC, Simpson MJC. Insulation workers in Belfast: a further study of mortality due to asbestos exposure (1940-75). Br J Ind Med 1977;34:174-80.

${ }^{7}$ Thomas HF, Benjamin IE, Elmwood PC, Sweetnam PM. Further follow-up study of workers from an asbestos cement factory. $\mathrm{Br} 3$ $J$ Ind Med 1982;39:273-6.

${ }^{8}$ Hughes J, Weill H. Lung cancer risk associated with manufacture $\frac{\mathrm{O}}{\supset}$ of asbestos-cement products. In: Biological effects of mineral $D$ fibres. Lyon: International Agency for Despatch on Cancer, 으 1980:627-35. (IARC Sci Pub No 30.)

${ }^{9}$ Berry G, Newhouse ML. Mortality of workers manufacturing fric- $\mathrm{N}$ tion materials using asbestos. Br J Ind Med 1983;40:1-7.

${ }^{10}$ Robinson CE, Lemen R, Wagoner JK. Mortality patterns $\mathrm{N}$ 1940-1975 among workers employed in an asbestos textile fric- N tion and packing products manufacturing facility. In: Lemen $\mathbf{R}, \omega$ Dement JM, eds. Dusts and diseases. Illinois: Patlotox, 1979:ত 131-43.

${ }^{11}$ Newhouse ML, Berry G. Patterns of mortality in asbestos factory workers in London. Ann NY Acad Sci 1979;330:53-60.

12 Henderson VL, Enterline PE. Asbestos exposure: factors associ- ated with excess cancer and respiratory disease mortality. Ann $\frac{T}{T}$ NY Acad Sci 1979;330:117-26

${ }^{13}$ Weill H, Hughes J, Waggenspack C. Influence of dose and fibre $\stackrel{\overparen{D}}{\circ}$ type in respiratory malignancy risk in asbestos cement manu- $\overrightarrow{(\mathbb{D}}$ facturing. Am Rev Respir Dis 1979;120:345-54.

${ }^{14}$ Doll R, Peto J. Effects on health of exposure to asbestos. London: HMSO, 1984. 